\title{
A CASE STUDY ON CLINICAL PHARMACIST INTERVENTIONS IN THE MANAGEMENT OF DIABETES COMPLICATED CORONARY ARTERY DISEASE IN HEALTH-CARE PRACTICE
}

\author{
BHARATH KUMAR A ${ }^{1}$, UMASHANKAR MS ${ }^{2 *}$ \\ ${ }^{1}$ Department of Pharmacy Practice, SRM College of Pharmacy, SRM Institute of Science and Technology, Kattankulathur, Tamil Nadu, India. \\ ${ }^{2}$ Department of Pharmaceutics, SRM College of Pharmacy, SRM Institute of Science and Technology, Kattankulathur, Tamil Nadu, India. \\ Email: sreebharathgroup1991@gmail.com \\ Received: 31 December 2019, Revised and Accepted: 01 February 2020
}

ABSTRACT

Objective: The objective of the study was to assess the clinical pharmacist interventions in the management of diabetes complicated coronary artery disease.

Methods: In the present study, a case history of a 55-year-old female was suffering from diabetes with coronary artery disease was taken. The case was collected from the cardiology outpatient department in a tertiary care hospital. The case was analyzed from 1 to 3 months. The initial visit to the end of final visit her laboratory parameters was examined at the laboratory.

Results: The test report of electrocardiogram revealed sinus rhythm. The patient was advised for an echocardiogram which confirmed coronary artery disease. The patient was subjected to a coronary angiogram, which revealed the presence of double-vessel disease. Her ankle-brachial index study test revealed peripheral artery disease. The patient was diagnosed with coronary artery disease, and she was prescribed with regular medications. The patient was monitored for 1-week duration and prescribed with coronary artery disease medications to normalize the condition. The patient was improved with the treatment and advised for regular follow-ups.

Conclusion: The study concludes that there was an imperative need for regular health screening by the physician associated clinical pharmacist care services with an effective treatment modality that can reduce the coronary artery disease incidences in this patient.

Keywords: Diabetes mellitus, Coronary artery disease, Peripheral artery disease, Clinical pharmacist service.

(C) 2020 The Authors. Published by Innovare Academic Sciences Pvt Ltd. This is an open access article under the CC BY license (http://creativecommons. org/licenses/by/4. 0/) DOI: http://dx.doi.org/10.22159/ajpcr.2020.v13i4.36742

\section{INTRODUCTION}

Coronary artery disease is a more health-care problem in the world and causes more number of health-care defects among diabetic patients. Diabetic patients have a higher risk of developing coronary artery disease as comparing with non-diabetic patients. The higher incidence of mortality and morbidity among coronary artery disease in diabetic patients which state that there is a need for clinical pharmacist interventions to improve the health-related outcomes of disease patients and to reduce the progression of risk incidences in the healthcare. The clinical pharmacist interventions were useful in the control of coronary artery disease risk factors to lower the progression of coronary artery disease in diabetic patients. The cardiac therapies and surgical procedures are highly expensive and increase the more health-care expenditure to the affected population [1,2]. The International Diabetes Federation predicted that worldwide 41 million people affected with diabetes mellitus, this number of affected population may rise to 642 million by 2040 . The novelty of this case report is dealt with the role of clinical pharmacist intervened services during the various follow-ups can help for the prevention of coronary artery disease among diabetic patients in an urban health-care practice. This is the first case report to demonstrate the need of clinical pharmacist services in the patient care areas to identify the cardiovascular disease risk patients and control of risk factors, educating the patients to adhere to the lifestyle modifications, medication adherence can ultimately improve the health-related quality of life among diabetic patients can support the rationality of this study. Regular health education, lifestyle modification, and maintaining the controlled levels of lipid, blood sugar, and blood pressure can reduce the progression of diabetic complications $[3,4]$.

\section{CASE REPORT}

A 55-year-old female patient came with clinical symptoms of chest pain that lasted for 7 days with chest discomfort, swollen legs, shortness of breath, and headache. She had a medical history of Type 2 diabetes mellitus with hypertension and a family history of coronary artery disease. She had previous medications such as oral hypoglycemic agents, antihyperlipidemic drugs, antiplatelet drugs, antihypertensive drugs, iron supplements, and proton-pump inhibitors which were used regularly by the patient. She regularly eats more quantity of meat, consumes salt food, pickles, and seafood weekly thrice.

\section{METHODS}

\section{Patient consent}

The patient consent was taken in written as well as in verbal communication to use her laboratory report in the present study.

\section{Laboratory test parameters}

Her fasting blood sugar was $177 \mathrm{mg} / \mathrm{dl}$, postprandial glucose was $210 \mathrm{mg} / \mathrm{dl}$, and glycosylated hemoglobin was 7.6. During the admission, her body weight was $85 \mathrm{~kg}$, height $180 \mathrm{~cm}$, body mass index was $26.2 \mathrm{~kg} / \mathrm{m}^{2}$, blood pressure was $160 / 90 \mathrm{mmHg}$, total cholesterol was $265 \mathrm{mg} / \mathrm{dL}$, triglyceride was $215 \mathrm{mg} / \mathrm{dl}$, very low-density level lipoprotein $45 \mathrm{mg} / \mathrm{dl}$, and low-density lipoprotein was $179 \mathrm{mg} / \mathrm{dl}$, and high-density lipoprotein was $23 \mathrm{mg} / \mathrm{dl}$. Her serum electrolytes sodium was $137 \mathrm{meq} / \mathrm{L}$ showing hypernatremia, potassium was $3.0 \mathrm{meq} / \mathrm{L}$, chloride was $99 \mathrm{mmol} / \mathrm{L}$, and bicarbonate was $28 \mathrm{mmol} / \mathrm{L}$. Her ankle-brachial index was 0.62 which detected peripheral artery disease. Electrocardiogram detected sinus rhythm. Echocardiogram revealed coronary artery disease, left ventricular ejection fraction of 
$50 \%$, and mild left ventricle systolic dysfunction with normal chamber dimensions. Aortic value sclerosis and Grade 1 left ventricle diastolic dysfunction were also found. A coronary angiogram exhibited coronary artery disease with double-vessel disease. The patient was subjected to coronary artery bypass graft with stent to the left anterior descending artery and also the placement of two stents in the right coronary artery was performed to the patient. Her hematological examinations revealed hemoglobin test was $9.9 \mathrm{~g} / \mathrm{dl}$, packed cell volume was 35\%, total white blood cells was $9700 / \mathrm{cum}$, neutrophils was $74 \%$, eosinophils was $6 \%$, basophils was $1 \%$, lymphocytes was $20 \%$, monocytes was $2 \%$, red blood cells was $3.9 \times 10^{6} / \mathrm{mm}^{3}$, erythrocyte sedimentation rate was $38 \mathrm{~mm} / \mathrm{h}$, mean corpuscular volume was $90 \mathrm{fl}$, mean corpuscular hemoglobin was $29 \mathrm{pg} /$ cell, mean corpuscular hemoglobin concentration was $33 \mathrm{~g} / \mathrm{dl}$, and platelets count was 2,28,000 cells/cum.

\section{RESULTS}

After collecting a report from the laboratory, it was observed that most of the clinical test parameters were abnormal. The patient was consulted physician and she received treatment from the physician and she has been referred to clinical pharmacist for counseling. The clinical pharmacist counseled the patient on medication use, lifestyle modifications, diet counseling, and her lifestyle were continuously monitored by the clinical pharmacist at regular intervals. From day 1 to 7 , the patient was asymptomatic and her health status was drastically improved. She discharged from hospital on day 8 after 1 day of clinical observation. The discharge medications consist of tablet rosuvastatin $10 \mathrm{mg}$ once daily (OD), tablet aspirin $75 \mathrm{mg}$ OD, tablet trimetazidine $35 \mathrm{mg}$ OD, tablet bisoprolol $2.5 \mathrm{mg}$ OD, tablet iron $50 \mathrm{mg}$ OD, tablet glimepiride $1 \mathrm{mg}$ OD, pantoprazole $40 \mathrm{mg}$ OD, and inj. Human Mixtard 30/70 U OD. The details are described in Table 1.

\section{DISCUSSION}

The above specified several clinical laboratory examinations revealed that the patient was having coronary artery disease associated with diabetes mellitus. In her first review visit to the hospital after 1-month duration, her laboratory parameters were abnormal. The clinical examinations were performed to her at a follow-up visit to identify the changes in the laboratory parameters. The effective clinical pharmacist intervened care services were provided to her at follow-ups.

The clinical pharmacist intervention counseling was provided to the patient on usage, indications, timely intake of medications, lifestyle modification with regular physical exercises 20-30 min walking every day for weight management, breathing exercises, etc. Diet contains low cholesterol, high fiber, and consumption of fruits and vegetables, stress management, less salt consumption counseling who was provided to the patient to control diabetes complications. The patient was advised to continue the prescribed medications with regular physician consultations. The end of clinical pharmacist intervention, her health condition was slightly improved. On the second review visit to the hospital, her laboratory investigations were found normal and the patient had completely recovered, Table 2 and Fig. 1 . The patient was suffering from diabetes-associated coronary artery disease and her coronary artery risk was evaluated by lipid levels, blood glucose levels, blood pressure, etc., in her continuous follow-up visits.

Our study results in comparison with Zhao et al., concluding that the regular implementation of clinical pharmacist services to the affected patients with scheduled follow-ups had showed large improvement in drug compliance, quality of life which minimized the severity of cardiovascular complications among the diabetic patients in health care practice [5]. Similar study by Chhajer et al. explained that the yoga-based lifestyle interventions can reduce the progression of cardiac events among high-risk cardiovascular disease patients [6]. Our study results meet with a similar study by Shao et al. concluded that the clinical pharmacist has a key role in diabetes management. The pharmaceutical care provided by the clinical pharmacist has improved medication adherence and also controlled levels of cholesterol and blood glucose levels in diabetic patients [7]. A similar study by Kandasamy et al. demonstrates that a significant reduction in the blood glucose and cholesterol levels was achieved by the clinical pharmacist counseling services to diabetic patients. The effective management of glycemic, blood pressure, and lipid levels can reduce the progression of diabetic complications [8].

Prompt identification of coronary artery disease risk patients and the implementation of effective treatment plans on disease management can reduce the occurrence of coronary artery disease risk burden of the individual patients. Early initiation of clinical pharmacist care services along with the health care team in the risk factors screening and lifestyle modification practices, regular physical exercise for 30 minutes, consumption of diabetic diet, avoiding the consumption of

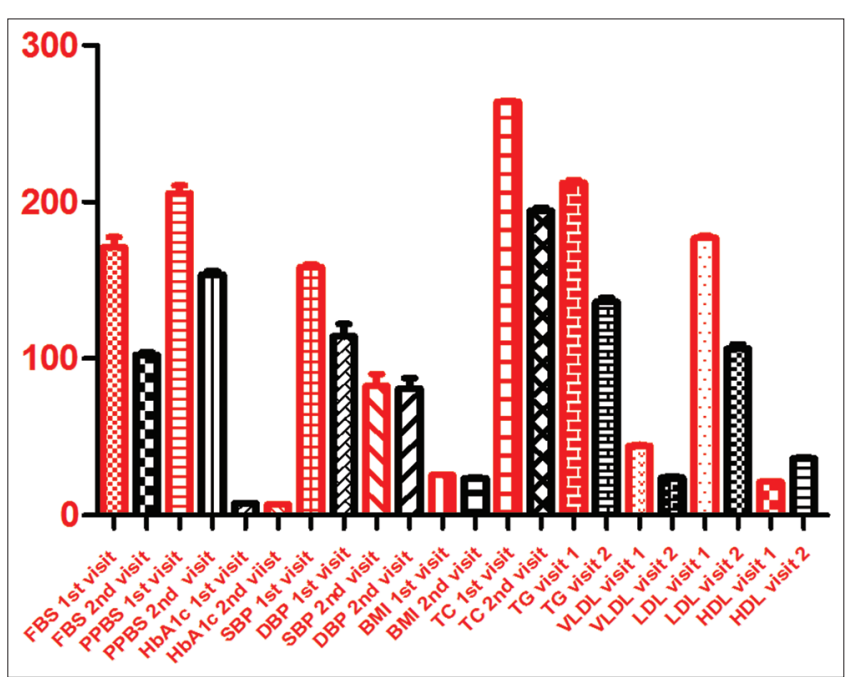

Fig. 1: Comparison of laboratory parameters from the first visit to second visit. FBS: Fasting blood sugar, PPBS: Postprandial blood sugar, HbA1c: Glycosylated hemoglobin, BMI: Body mass index, TC: Total cholesterol, TG: Triglyceride, VLDL: Very low-density lipoprotein, LDL: Low-density lipoprotein, HDL: High-density lipoprotein

Table 1: Prescribed medications chart

\begin{tabular}{|c|c|c|c|c|c|}
\hline S. No. & Medications & Dose & Frequency & Route & Indications \\
\hline 1. & Tablet rosuvastatin & $10 \mathrm{mg}$ & OD & Oral & Lower cholesterol \\
\hline 2. & Tablet aspirin & $75 \mathrm{mg}$ & OD & Oral & Prevents blood clot, relieves chest pain \\
\hline 3. & Tablet trimetazidine & $35 \mathrm{mg}$ & OD & Oral & Treatment of chest pain \\
\hline 4. & Tablet bisoprolol & $2.5 \mathrm{mg}$ & OD & Oral & Lower blood pressure \\
\hline 5. & Tablet iron & $50 \mathrm{mg}$ & OD & Oral & Iron supplement \\
\hline 6. & Tablet glimepiride & $2 \mathrm{mg}$ & OD & Oral & Lowers blood glucose \\
\hline 7. & Tablet pantoprazole & $40 \mathrm{mg}$ & OD & Oral & Treatment of peptic ulcer \\
\hline
\end{tabular}

OD: Once daily, SC: Subcutaneous 
Table 2: Comparison of laboratory parameters from the first review to second review

\begin{tabular}{lll}
\hline Parameters & $\begin{array}{l}\text { First visit } \\
\left(\mathbf{1}^{\text {st }} \text { month }\right)\end{array}$ & $\begin{array}{l}\text { Second visit } \\
\left.\mathbf{( 3}^{\text {rd }} \text { month }\right)\end{array}$ \\
\hline FBS & $171.0 \pm 6.60$ & $102.3 \pm 1.87$ \\
PPBS & $205.6 \pm 5.10$ & $153.5 \pm 2.35$ \\
HbA1c & $7.50 \pm 0.12$ & $6.90 \pm 0.15$ \\
Systolic blood pressure & $158.7 \pm 1.49$ & $82.50 \pm 7.53$ \\
Diastolic blood pressure & $114.2 \pm 7.93$ & $80.83 \pm 6.68$ \\
BMI & $25.50 \pm 0.67$ & $23.67 \pm 0.49$ \\
TC & $264.0 \pm 0.85$ & $194.4 \pm 2.06$ \\
TG & $212.3 \pm 1.86$ & $136.4 \pm 2.35$ \\
VLDL & $44.25 \pm 0.86$ & $23.75 \pm 1.21$ \\
LDL & $177.1 \pm 1.16$ & $106.4 \pm 2.77$ \\
HDL & $21.25 \pm 0.62$ & $36.25 \pm 0.75$ \\
\hline
\end{tabular}

${ }^{*} \mathrm{p}<0.0001$ FBS: Fasting blood sugar, PPBS: Postprandial blood sugar HbA1c: Glycosylated hemoglobin, BMI: Body mass index, TC: Total cholesterol, TG: Triglyceride, VLDL: Very low-density lipoprotein, LDL: Low-density lipoprotein, HDL: High-density lipoprotein

fatty foods, regular medication adherence informations and knowledge enhancement to the affected patient can control the levels of risk factors which could prevent the future occurrences of coronary artery diseases $[9,10]$.

Globally, the prevalence of diabetes mellitus is increased rapidly which leads to cause more health-care expenditure to the individual patients. The International Diabetes Federation estimated that diabetes mellitus is expected to raise 592 million by 2035. Cardiovascular diseases cause more count of death worldwide. Patients with high level of cholesterol, uncontrolled diabetes mellitus and more stress, lack of health screening and poor treatment modalities can aggravate the risk of coronary artery disease risk incidences. Patients with a family history of cardiovascular disease, hypertension can elevate the coronary artery disease burden in the clinical practice [11,12]. The origin of coronary artery disease in diabetes mellitus is associated with several pathophysiological mechanisms which include hyperglycemia and insulin resistance can impair the platelet cells function in the blood vessels which causes plaque formation and lowers the blood flow to the heart which increase the risk of coronary artery disease complications in diabetic patients. Clinical pharmacy is an integral part of the healthcare system. The presence of a clinical pharmacist in the wards and outpatient departments can assist the physician in optimizing the pharmacotherapy. The clinical pharmacist can collaborate with the health-care team in the detection of cardiovascular risk factors, prevention, and management of cardiovascular diseases. Clinical pharmacist has an essential role in the design of research protocol, newer guidelines for blood sugar control, calculation of insulin dose, monitoring patient's blood pressure, glycemic level, lipid levels, solving drug-related problems, and reconciliation of discharge drugs $[13,14]$. The active involvement of clinical pharmacist in diabetes-associated cardiovascular disease control and also suggesting the physicians prescribes effective drug regimen to manage the diabetic complicated cardiovascular in this patient $[15,16]$. The above clinical pharmacist interventions, the patient is reported that she had a controlled level of hyperglycemic events. Therefore, the clinical pharmacist should be present as a health-care team member in the management of diabetic complications at hospitals to improve the patient clinical outcomes.

\section{CONCLUSION}

Early detection and treatment can lower the risk burden of coronary artery disease. In the current juncture of patient's treatment, a team panel of health-care assistance with a prime role of a clinical pharmacist intervention seems to play a major effect on health-care management of coronary artery disease [17]. Professionally skilled clinical pharmacist can provide their services on patient's counseling and assistance is a vital need of the hour. The clinical pharmacist can render their services in all health-care centers which can ultimately make a benefit for the management of diabetes-associated coronary complications among the patient which will drastically reduce the risk burden of the disease as well as the cost of treatment $[18,19]$.

\section{ACKNOWLEDGMENT}

We thank our respectful Dean Dr. K.S. Lakshmi, SRM College of Pharmacy, SRM Institute of Science and Technology, Kattankulathur, for her continuous help, support, and encouragement.

\section{AUTHORS' CONTRIBUTIONS}

Bharath Kumar A: Concept, design, collection of data, laboratory investigations, interpretation of data, drafting a final report, the examination of patients on follow-up, and approval of the article to be published. Umashankar MS: Concept, design, collection of data, laboratory investigations, interpretation of data, drafting a final report, the examination of patients on follow-up, revising of article, and approval of the article to be published.

\section{CONFLICTS OF INTEREST}

The authors declare no conflicts of interest.

\section{AUTHORS FUNDING}

Nil.

\section{REFERENCES}

1. Chen J, Zhang Y, Liu J, Chen MH, Guo YL, Zhu CG, et al. Role of lipoprotein(a) in predicting the severity of new on-set coronary artery disease in Type 2 diabetics: A Gensini score evaluation. Diab Vasc Dis Res 2015;12:258-64.

2. Valensi P, Avignon A, Sultan A, Chanu B, Nguyen MT, Cosson E. Atherogenic dyslipidemia and risk of silent coronary artery disease in asymptomatic patients with Type 2 diabetes: A cross-sectional study. Cardiovasc Diabetol 2016;15:104

3. Duckworth W, Abraira C, Moritz T, Reda D, Emanuele N, Reaven $\mathrm{PD}$, et al. Glucose control and vascular complications in veterans with Type 2 diabetes. N Engl J Med 2009;360:129-39.

4. Hammoud T, Tanguay JF, Bourassa MG. Management of coronary artery disease: Therapeutic options in patients with diabetes. J Am Coll Cardiol 2000;36:355-65.

5. Zhao SJ, Zhao HW, Du S, Qin YH. The impact of clinical pharmacist support on patients receiving multi-drug therapy for coronary heart disease in China. Indian J Pharm Sci 2015;77:306-11.

6. Chhajer B, Singh V, Kumari G, Lohmor M. Effect of yoga based lifestyle intervention on coronary artery disease patients. Biomed Pharmacol J 2018;11:1275-89.

7. Shao H, Chen G, Zhu C, Chen Y, Liu Y, He Y, et al. Effect of pharmaceutical care on clinical outcomes of outpatients with Type 2 diabetes mellitus. Patient Prefer Adherence 2017;11:897-903.

8. Kandasamy K, Konakalla M, Sam R, Sebastian J, Natarajan A, Rajagopal SS, et al. A pilot study on the impact of pharmacist intervention in Type-2 diabetes mellitus counselling program in a rural community. Indian J Pharm Sci 2017;79:701-706

9. Beckman JA, Creager MA, Libby P. Diabetes and atherosclerosis: Epidemiology, pathophysiology, and management. JAMA 2002;287:2570-81

10. Tazhiyeva A, Reznik V, Abylayuly Z, Kozhayeva GK. The opinion of therapists and specialized doctors on the provision of medical assistance of patients with Type 2 diabetes in polyclinics in almaty. Int J App Pharm 2019;11:30-6.

11. Sauriasari R, Sakti RM. Impact of a pharmacist-led patient education initiative on glycemic control of patients with Type 2 diabetes mellitus: A single-center experience in West Jakarta, Indonesia. Int J Appl Pharm 2018;10:252-6.

12. Presetiawati $N 2^{\text {nd }}$, Andrajati R, Sauriasari R. Effectiveness of a medication booklet and counseling on treatment adherence in Type 2 diabetes mellitus patients. Int J Appl Pharm 2017;19:28-31.

13. Adikusuma W, Qiyaam N. Adherence level and blood sugar control of Type 2 diabetes mellitus patients who gets counseling and short messages service as reminder and motivation. Asian J Pharm Clin Res 2018;11:219-22. 
14. Manikandan R, Sudha NS, Logaraj M. Assessment of medication adherence among patients with hypertension and diabetes mellitus in urban field practice. Asian J Pharm Clin Res 2018;11:130-2.

15. Jain R, Jain P, Jain P. A review on treatment and prevention of diabetes mellitus. Int J Curr Pharm Res 2016;8:16-8.

16. Rabba AK, Aljiris WS, Ahmed NJ, Alkharfy KM. Short communication medication adherence in Type 2 diabetic patients: A study in Saudi Arabia. Int J Pharm Pharm Sci 2017;9:9-12.

17. Omar MS, San KL. Diabetes knowledge and medication adherence among geriatric patient with Type 2 diabetes mellitus. Int J Pharm Pharm Sci 2014;6:103-6.

18. Adepu R, Madhu S. Influence of post discharge counseling on health outcomes in diabetic and hypertensive patients. Asian J Pharm Clin Res 2011;4:28-33

19. Cohen LB, Taveira TH, Khatana SA, Dooley AG, Pirraglia PA, Wu WC. Pharmacist-led shared medical appointments for multiple cardiovascular risk reduction in patients with Type 2 diabetes. Diabetes Educ 2011;37:801-12. 